\title{
Micro-Marsupialization: A Novel Non-Surgical Method to Treat Mucocele in Children
}

\author{
Garima Khandelwal* \\ Khandelwal Dental Clinic, India
}

Received: September 28, 2016; Accepted: October 04, 2016; Published: October 30, 2016

*Corresponding author: Garima Khandelwal, Khandelwal Dental Clinic, India, Tel: +971559355171; E-mail: drgarima19@yahoo.com

\begin{abstract}
Treating Mucoceles in small children is a complicated task as small children do not sit still and cooperate during surgical procedures. Also, on seeing the surgical armamentarium required for removal of a mucocele and suturing, many small children and their parents become anxious and fearful. The location and size of the lesion also dictates, whether the surgery has to be done under GA or LA. This technique involves passing of 1 or more sutures through the base of the lesion to create alternate drainage pathway for the collected mucus so that the cyst dissolves and dissipates by itself thereby avoiding surgery. Micromarsupialization is a wonderful non invasive, comfortable technique for both patient and operator, with a decent percentage of successive rate.
\end{abstract}

Keywords: Mucocele; Marsupialization; Suture; Noninvasive; Ranula; Conservative;

\section{Introduction}

Mucocele is one of the most common lesion of the oral mucosa resulting from either trauma or change in the drainage system of the salivary glands resulting in mucous accumulation. They are benign lesions, usually painless, depending where they are located. They do cause discomfort though and create trouble especially in Pediatric population. Based on how the lesion has occurred they are classified in 2 categories. If there is a breach in the duct of the salivary gland, it results in oozing out of the mucous in surrounding tissue, giving rise to mucous Extravasation Cyst. $[1,2]$ But if there is obstruction of the duct, the mucous that is being produced starts getting collected within the salivary gland itself giving rise to mucous retention cyst. These cysts may be present for weeks or months before patient seeks for treatment due to their painless nature. Equal gender predilection is seen in children and recurrence rate is high. The aim of this paper is to provide a noninvasive approach to treat mucoceles in oral cavity in a painless, cost effective way with less time duration and maximum patient cooperation with significantly reduced anxiety in patients and their parents.

\section{Etiopathology}

Pathology of Mucocele is usually due to trauma, lip biting habit or accidental injury to the salivary glands due to any reason. The lesions can be sessile or pedunculated varying in sizes. Evolution is rapid or slow with periods of remission and exacerbation. [8-10] Lip Mucoceles are usually located on lateral area of lower lip. Ranula is mucoceles present in floor of the mouth which may extend bilaterally resulting in difficulties while speaking and swallowing. Histopathologically, these lesions are surrounded by granulation tissue characterized by an epithelial lining preferentially.

Prognosis is favorable and several treatments have been proposed in the literature, such as excision of the lesion associated or not with removal of the gland involved,

Marsupialization, cryosurgery, laser and micromarsupialization. Redish [16] reported that the placement of a wire suture through the lesion is a method of treatment that may be utilized for ranulas.

Based on the size of the lesion and cooperation of child, these lesions are treated under LA chair side or under GA. Treating a child patient GA for just a Mucocele is not feasible most of the times. In an adult too, if there is a huge ranula present on the floor of the mouth or the ventral surface of the tongue, treating under LA becomes very difficult as manipulating tongue position in a conscious patient is complicated. Treating a child patient GA for just a Mucocele is not feasible most of the times. Micromarsupialization is a minimally invasive technique carried out under topical anesthesia, and the procedure is carried out by draining the accumulated saliva and creating a new epithelialized tract along the path of the sutures; however, the required procedure time is approximately $5 \mathrm{~min}$ with no tissue damage or inflammation. [3, 4, 11, 12].

The following is a description of 2 case reports of Micromarsupilization procedure carried out in a 12 year old and 28 year old patients.

\section{Case Report 1}

A 10 year old girl reported with a cystic swelling on the ventral surface of the tongue present since 20 days. The gradually increasing cystic lesion caused the patient pain and difficulty in swallowing. No significant medical or history of allergy was recorded. On clinical examination, a 3.5 x $3 \mathrm{~cm}$ cystic lesion (Fig.1 \& 2) was seen on ventral surface of the tongue, which 
was painful to palpation. The lesion was sessile, soft and noninfected. After obtaining consent from the patient and the parent, micromarsupialization technique was planned for the patient on the same day.

\section{Case Report 2}

A 28 year old female sustained injury over her left floor of mouth mucus membrane while having a sharp Nachos for dinner. She experienced gradually rapid increase in the ranula over next 3 days which caused difficulty while deglutition. She reported with a $2.5 \times 3.5 \mathrm{~cm}$ Mucocele on her left floor of the mouth (Fig 6). Though she herself was a dentist, she insisted to try with Micromarsupiliazation technique first rather than proceeding with surgical excision due to invasiveness of the surgical procedure. Micromarsupilization technique with 2 sutures in different directions was carried out the same day.

\section{Material and Method}

Micro-marsupialization was performed according to the following technique: After disinfecting the area with Betadine solution, Topex Spray was applied (Benzoczine 20\%) over the entire lesion. Local anesthesia with $2 \%$ lignocaine with 100,000 Adrenalin was given submucosaly in the tissue surrounding the lesion. 3.0 silk sutures were passed through the widest diameter of the lesion from the base and a surgical knot was made in Case 1 (Fig 3). In Case 2, two sutures were passed (Fig 4), in different directions as the lesion was large and single suture may not have been sufficient enough to drain the mucous efficiently. The Mucocele was then compresed to help extravasation of mucus. $0.5 \%$ chlorhexidine gel was applied postoperatively to preven $t$ secondary infection. In case 1 suture were removed after 15 days and in case 2 sutures were removed after 30 days resulting in complete remission of the lesion. Follow up after 1 year did not show any remission. (Fig 4, 5 \& 8).

\section{Discussion}

Although micro-marsupialization has been described in the literature since 2000, mainly for the treatment for ranulas, its use in the treatment for other mucoceles has been limited. The micromarsupialization technique was selected because it is of simple execution, less traumatic, and well tolerated by the patient. The most important advantage of this technique is virtually no bleeding and zero side effect. Even if th4e lesion does not resolve with this technique at any point surgical excision can be easily carried out. These are fundamental features to be considered in pediatric dentistry. Simple incision and drainage will result in recurrence of mucus retention phenomena. The introduction of a suture presumably maintains a tract while permitting an epithelial tract to form between the surface and the underlying salivary glandular tissues $[13,14,15]$.

In Case no. 1, since the child was young, and the mucocele large in size that too on the ventral surface of the tongue, excising it under local anesthesia would have been very challenging considering the longer duration of cooperation expected out of the patient and holding the tongue in position
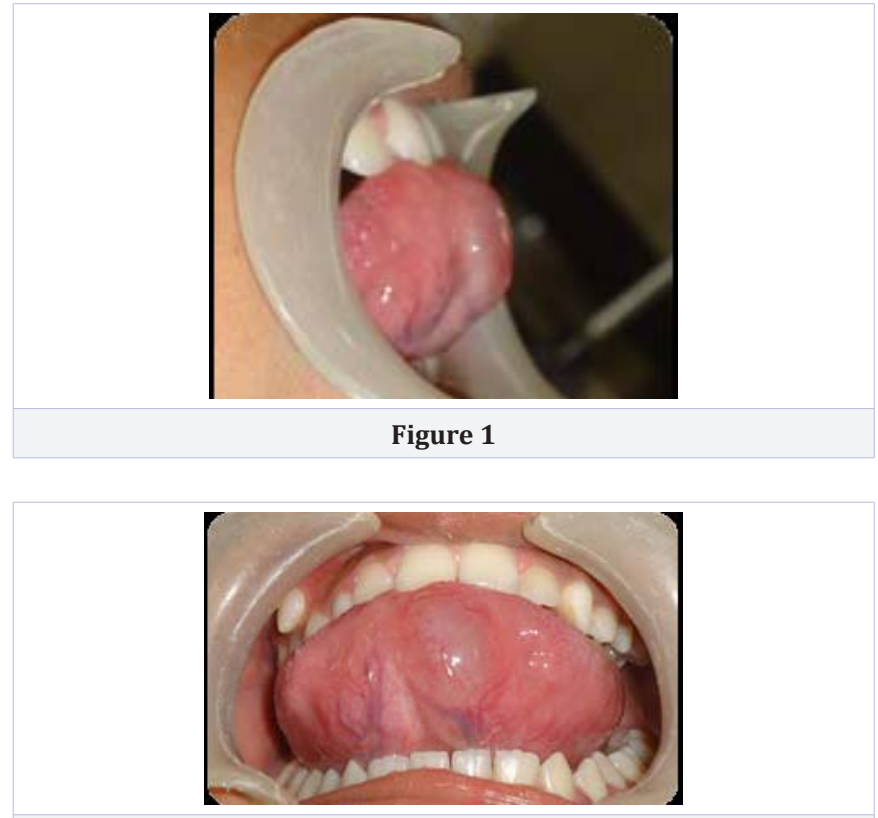

Figure 2

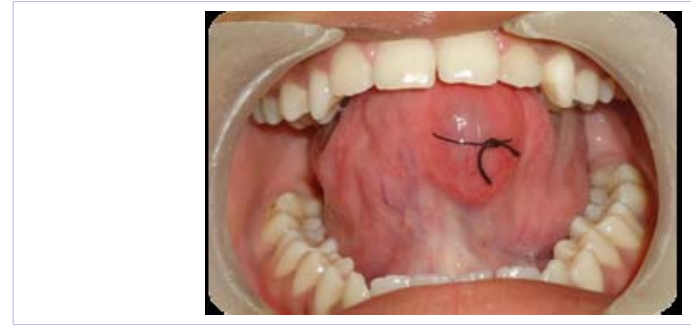

Figure 3

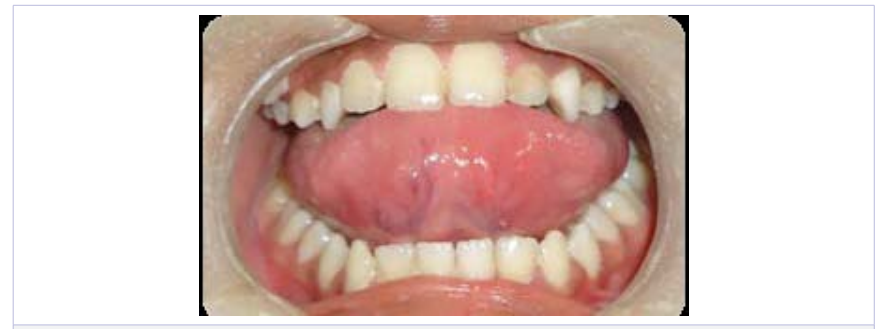

Figure 4

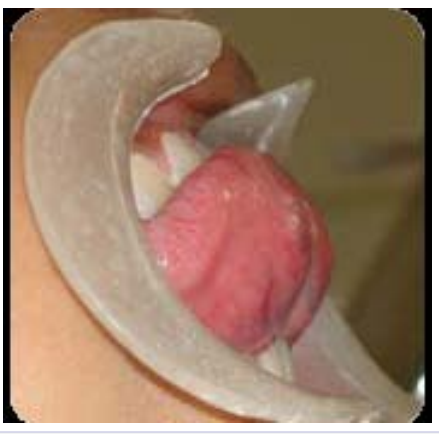

Figure 5 
during surgical procedure. Treating the patient under general anesthesia would have been the treatment of choice. Opting for micromarsupilization, not only reduced the surgical time, but also saved the patient from day care surgical procedure causing patient minimum discomfort.

This technique has found to be very effective in small mucoceles on lip, cheek and other areas of oral cavity, especially in young children who can cooperate thereby saving the surgeon the time and efforts required in excision, giving the same results. Even if micromarsupilization technique fails, or a recurrence occurs, the lesion can always be treated by more definitive methods as mentioned earlier. Micromarsupilization is the harmless and easiest technique to be tried before opting for a surgical approach

Marsupialization is a surgical technique that involves incising into a cyst and suturing the edges of the subsequent slit to form a continuous surface from the exterior to the interior of the cyst. [5, 6] Micro-marsupialization consists in draining the accumulated saliva and creating new epithelialized tracts along

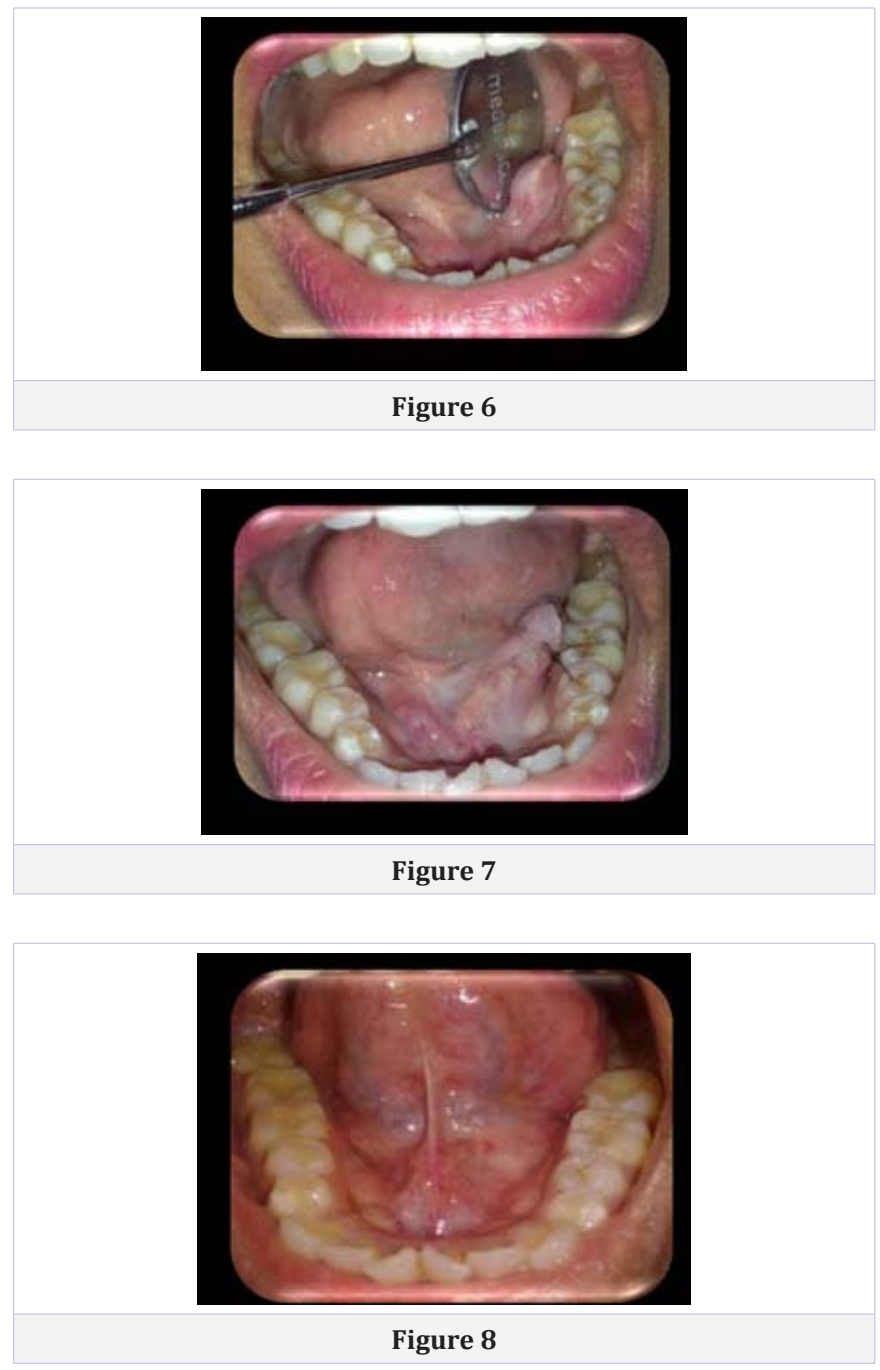

the path of the sutures. It is a minimally invasive technique, and most cases can be carried out under topical anesthesia alone. The required procedure time is brief (approximately $3 \mathrm{~min}$ ), there is practically no tissue damage or inflammation, and it appears to be a particularly suitable technique for children who cannot tolerate long or invasive procedures

Micromarsupialization does not enable a biopsy to be conducted, and the diagnosis remains exclusively clinical.[17] Furthermore, it should be carefully used in palatal or buccal lesions, as minor salivary gland tumors are often located in those areas and can be wrongly diagnosed as mucoceles.

\section{Conclusion}

This study suggests that micro-marsupialization could be a treatment option for children and adolescents with mucoceles. It is simpler to perform, minimally invasive, requires no local infiltration of anesthesia, has a lower postoperative complications rate, and is well tolerated by patients.

\section{References}

1. Black RJ, Croft CB. Ranula: pathogenesis and management. Clin Otolaryngol. 1989;7:299-303. DOI: 10.1111/j.1365-2273.1982. tb01910.x.

2. Oliveira DT, Consolaro A, Freitas FJG. Histopahological spectrum of 112 cases of mucocele. Braz Dent J. 1993;4(1):29-36.

3. Shafer WG, Hine MK, Levy BM. Lesões físicas e químicas da cavidade bucal. In Tratado de Patologia Bucal. $4^{\mathrm{a}}$ Ed. Rio de Janeiro: Guanabara.1985; 512-515.

4. Yamasoba T, Tayama N, Syoji M. Clinicostatistical study of lower lip mucoceles. Head Neck. 1990;12(4):316-20.

5. Castro AL. Glândulas salivares. In Estomatologia, 2 $2^{\underline{a}}$ Ed. São Paulo: Santos. 1995;152-54

6. Kang SK, Kim KS. Clinical and histopathologic study of salivary mucoceles. Taehan-Chikkwa-Uisa-Hyophoe-Chi. 1989;27(11):10591071.

7. Mandel L. Ranula, or, what's in a name? N Y State Dent J.1996;62(1):3739.

8. Yoshimura Y, Obara S, Kondoh T, Naitoh S. A comparison ofthree methods used for treatment of ranula. J Oral Maxillofac Surg. 1995;53(3):280-282.

9. Baurmash HD. Marsupialization for treatment of oral ranula. J Oral Maxillofac Surg. 1992;50(12):1274-1279.

10. Bodner L, Tal H. Salivary gland cysts of the oral cavity. clinical observation and surgical management. Compend Contin Educ Dent. 1991;12(3):150-156.

11. Mı́nguez-Martinez I, Bonet-Coloma C, Ata-AliMahmud J, CarrilloGarcı'a C, Peñ arrocha-Diago M, Peñ arrocha-Diago M. Clinical characteristics, treatment, and evolution of 89 Mucoceles in children. J Oral Maxillofac Surg 2010;68(10): 2468-2471.

12. Neville B, Damn DD, Allen CM, Bouquot JJ. Oral \& Maxilofacial Pathology, 2nd edn. Philadelphia: W. B. Saunders, 2002: 389-392.

13. Harrison JD. Salivary mucoceles. Oral Surg Oral Med Oral Pathol 1975; 39: $268-278$. 
14. Bermejo A, Aguires JM, Lopez P, Saez MR. Superficial mucocele: report of 4 cases. Oral Surg Oral Med Oral Pathol Oral Radiol Endod 1999; 88 : 469-472.

15. Mandel L. Multiple superficial oral mucoceles: case report. J Oral Maxillofac Surg 2001; 59: 928-930.

16. Garofalo S, Briganti V, Cavallaro S, Pepe E, Prete M, Suteu L et al. Nickel gluconate-mercurius heel-potentised swine organ preparations: a new therapeutical approach for the primary treatment of pediatric ranula and intraoral mucocele. Int J Pediatr Otorhinolaryngol. 2007; 71(2): 247-255. DOI: 10.1016/j.ijporl.2006.10.013.

17. Roh JL, Kim HS. Primary treatment of pediatric plunging ranula with nonsurgical sclerotheraphy using OK-432 (Pinivanil). Int J Pediatr Otorhinolaryngol. 2008;72(9):1405-1410. doi: 10.1016/j. ijporl.2008.06.003.

18. American Academy on Pediatric Dentistry, American Academy of Pediatrics: Policy on Early Childhood Caries (ECC): Classifications, Consequences, and Preventive Strategies. Pediatr Dent 20082009;30:40-43.

19. Estela M. Losso, Maria Cristina R. Tavares, Juliana Y. B. da Silva, Cícero de A. Urban. Severe early childhood caries: an integral approach. Pediatr (Rio J). 2009; 85(4):295-300. doi:10.2223/JPED.1908.

20. Management of Severe Early Childhood Caries. 2nd Edition. 2012.

21. Sobia Zafar, Soraya Yasin Harnekar, Allauddin Siddiqi. Early childhood caries: etiology, clinical considerations, consequences and management. International dentistry SA. 2009;11(4):24-36.

22. Fung MHT, Wong MCM, Lo ECM, CH Chu. Early Childhood Caries: A Literature Review. Oral Hyg Health. 2013;1: 107. doi:10.4172/23320702.1000107.

23. Robert J. Berkowitz. Causes, Treatment and Prevention of Early Childhood Caries: A Microbiologic Perspective. J Can Dent Assoc. 2003;69(5):304-307

24. Annerosa Borutta, Maik Wagner, Susanne Kneist. Early Childhood Caries: A Multi-Factorial Disease. OHDMBSC. 2010;IX(1):32-38.

25. Mi-ae Jeong, Ah-hyeon Kim, Youn-soo Shim, So-youn An. Restoration of Strip Crown with a Resin-Bonded Composite Cement in Early Childhood Caries. Case Reports in Dentistry. 2013; doi: 10.1155/2013/581934.

26. Carmelo GA Nobile, Leonzio Fortunato, Aida Bianco, Claudia Pileggi,
Maria Pavia. Pattern and severity of early childhood caries in Southern Italy: a preschool-based cross-sectional study. BMC Public Health. 2014;14:206. DOI: 10.1186/1471-2458-14-206

27. Steven Schwartz. Full Coverage Aesthetic Restoration of Anterior Primary Teeth. Crest $\AA$ Oral-B $\AA$ at dentalcare.com Continuing Education Course.2015.

28. Suzan Sahana, Aron Arun Kumar Vasa, Ravichandra Sekhar. Esthetic crowns for primary teeth: a review. Annals and Essences of Dentistry. 2010;II(2):87-93.

29. www.http://solutions.3mae.ae.

30. Webber DL, Epstein NB, Wong JW, Tsamtsouris A. A method of restoring primary anterior teeth with the aid of a celluloid crown form and composite resins. Pediatr Dent. 1979;1(4):244-246.

31. Eidelman E, Faibis S, Dr. Odont, Peretz B. A comparison of restorations for children with Early Childhood Caries treated under general anesthesia or conscious sedation. Pediatr Dent. 2000;22(1):33-37.

32. Kupietzky A, Waggoner WF, Galea J. The clinical and radiographic success of bonded resin composite strip crowns for primary incisors. Pediatr Dent.2003;25(6):577-581.

33. Ram D, Fuks AB. Clinical performance of resin-bonded composite strip crowns in primary incisors: a retrospective study. Int J Paediatr Dent. 2006;16(1):49-54. DOI: 10.1111/j.1365-263X.2006.00680.x.

34. Deep Karan S. Dhillon, Cody C. Hughes, Connie C. Mobley. Comparison of preveneered stainless steel crowns to resin-bonded strip crowns for the restoration of primary maxillary incisors. NDA Journal. Winter 2013-2014, 15(4): 18-21

35. Alireza Eshghi, Raha Kowsari-Isfahan, Maryam Khoroushi. Evaluation of Three Restorative Techniques for Primary Anterior Teeth with Extensive Carious Lesions. A 1-year Clinical Study. Journal of Dentistry for Children.2013;80(2):80-87.

36. Walia T, Salami AA, Bashiri R, Hamoodi OM, Rashid F. A randomised controlled trial of three aesthetic full-coronal restorations in primary maxillary teeth. European Journal of PaediaticDentistry. 2014;15(2):113-118.

37. Duhan H, Pandit IK, Srivastava N, Gugnani N, Gupta M, Kochhar GK. Clinical comparison of various esthetic restorative options for coronal build-up of primary anterior teeth. Dent Res J (Isfahan). 2015;12(6):574-580. 